\title{
Production of Single Cell Protein from Fruit and Vegetable Waste using
} Saccharomyces cerevisiae

\author{
Savi Ahuja and Poonam Kumari*
}

Microbiology Laboratory, Department of Microbiology, Shoolini Institute of Life Sciences and Business Management, The Mall-173212, Solan, Himachal Pradesh, India

*Corresponding author:

\section{A B S T R A C T}

Keywords

SCP, Yeast, apple peels, Orange peels, Tomato peels, Pea, Saccharomyces cerevisiae

Article Info

Accepted:

04 January 2019

Available Online:

10 February 2019
Protein accounts for the major requirement of the human body, as the Dietary Reference Intake (DRI) of protein is 0.8g.per kilogram of body weight. The Indians have been reported deficient of major amino acids according to the surveys conducted in recent years. Single cell protein (SCP) represents microbial cells grown in mass culture that are harvested as dried cell mass in the form of natural protein concentrate. In the present studies apple, orange, tomato and pea peels were used as the substrate to grow Saccharomyces cerevisiae strains to obtain single cell protein. On estimating the protein obtained by Lowry's method the maximum quantity was 6.7 milligrams per milliliter $(\mathrm{mg} / \mathrm{ml})$ from pea peels and thin-layer chromatography (TLC) confirmed it to be a good mixture of essential and non-essential amino acids.

\section{Introduction}

The protein deficiency has become a major threat to the world today. In relevance to India, 60 percent of the protein is derived from the cereals with relative low digestibility and quality. The continuous increase of population in the developing countries has led to the increasing demand of nutritious food which is supplemented with all the required nutrients such as proteins, vitamins, minerals. To meet the demands the industries came up with synthetic supplements commonly called 'multivitamins' which are further non- digestible and cause allergic reaction and hypersensitiveness. Therefore, there is a great demand for organic and natural supplement alternatives in daily diet. Thus, single cell protein arises as a perfect administration of United States of America (Gervasi et al., 2018) Alternative to conventional sources for food and feed. Single cell proteins are the dried cells of microorganisms, which are used as protein supplements in human food or animal feeds. Various microorganisms like algae, fungi, yeast and bacteria have been cultured on waste materials as substrates to obtain protein concentrate. They have a very 
high nutritive value due to high concentration of essential amino acids such as leucine, valine, threonine, cysteine and lipid content.

India stands second to produce fruits and vegetables in the world. According to the Agricultural Research Data Book 2004 (Chandak et al., 2016), waste generated from fruits and vegetables accounts to 50 million tons per annum and this waste is a rich source of carbohydrates that supports the growth of microorganisms.

Agricultural waste used for single cell protein production proves to be a cheap and economic substrate and also helps in management of waste.

The algal protein has been the most highlighted name in the world of single cell proteins, however this protein is indigestible and toxic whereas yeast is quite familiar and widely accepted microorganism in traditional fermentations and can also be used for production of single cell protein because of its large size, low nucleic acid content, high lysine content and less accumulation of toxins. This organism has been granted with "Generally recognized as safe" (GRAS) by the food and drug

The consumption of microorganisms by humans is not a revolutionary step because intentionally or unintentionally the intake of microorganisms has been an old practice in commonly fermented products such as cheese, alcohol, yoghurt. The population demands for good economic products and waste management.

Thus, the present investigation was carried out to manage and reuse fruit and vegetable waste to manufacture single cell protein. The peels of apple, orange, tomato and pea were used as carbon sources enriched with required nutrients to culture Saccharomyces cerevisiae.

\section{Materials and Methods}

\section{Collection of samples}

Peel samples from apple, orange, tomato and pea were collected from the local market of Solan, Himachal Pradesh.

Isolation of Saccharomyces sp (Yadav et al., 2016)

The Saccharomyces sp. was isolated from the bread sample and was serially diluted.

The dilutions were later spreaded on Potato dextrose agar and finally the plates were incubated at $30^{\circ} \mathrm{C}$ for 3days.

\section{Identification of Saccharomyces cerevisiae}

Saccharomyces cerevisiae was identified using following tests from the mixed population of microorganisms:

\section{Yeast viability test (Tong et al., 2004)}

This test involved simple staining of microbial cells with methylene blue to study the viability of yeast cells.

A small amount of culture was taken on the slide and flooded with methylene blue until dried. The slide was then observed under the microscope.

\section{Lacto phenol cotton blue staining (Acharya 2014)}

The LCB staining was performed to study the morphological structures of fungi. A small amount of culture was taken on a slide and spreaded to obtain a thin film.

This film was stained with a drop of LCB and covered with a cover slip. The slide was then observed under $40 \mathrm{X}$ objective. 
Test for hydrolysis of urea (Yadav et al., 2016)

This test was carried out on Christensen's urease agar slants to test the ability of the organism to produce the enzyme urease and cause hydrolysis of urea. Thus, the obtained organism was streaked on Christensen's urease agar slants and incubated at $25^{\circ} \mathrm{C}$ for 48 hours.

Hydrogen sulphide production (Yadav et al., 2016)

This test was performed on Bismuth sulphite agar to test the ability of an organism to reduce sulfur-containing compounds to sulphite during metabolism. Therefore, the organism was inoculated on the medium for 48 hours and observed for color change.

\section{Preparation of sample extracts (Chandak et al., 2014)}

40 grams of each selected fruit and vegetable peels were hydrolyzed using 10 percent $\mathrm{HCl}$ and incubated in the water bath for an hour at boiling tempreture. The mixture was cooled and then filtered through muslin cloth. The filtrates were used as carbon and nitrogen supplements for the growth of an organism.

Fermentation and harvesting of single cell protein (Chandak et al., 2014)

The supplemented fruit hydrolysate medium was prepared. The sample extracts obtained were added with ammonium sulphate 2 grams, monopotassium phosphate 1 grams, magnesium sulphate heptahydrate $0.5 \mathrm{grams}$, sodium chloride 0.1 grams, calcium chloride 0.1 grams and glucose 2 grams to it. The final volume was made to 1litre and $\mathrm{pH}$ was adjusted to 5.5. The medium was autoclaved at $121^{\circ} \mathrm{C}$ for 15 minutes and cooled. Each medium was added with 2 millilitre of $S$. cerevisiae culture and incubated at $28^{\circ} \mathrm{C}$ for an interval of 4-6-8 days.

\section{Protein estimation and analysis}

Physical analysis (Chandak et al., 2014)

The protein obtained was physically analyzed through wet and dry weight.

\section{Chemical analysis}

\section{Lowry's method (Lowry et al., 1951)}

The protein amount obtained was determined using Lowry's method. The alkaline reagent was prepared using 1 percent copper sulphate $\left(\mathrm{CuSO}_{4}\right), 1$ percent sodium potassium $(\mathrm{Na} . \mathrm{K})$ tartarate and 2 percent sodium carbonate $\left(\mathrm{Na}_{2} \mathrm{CO}_{3}\right)$ in $0.1 \mathrm{~N}$ (normality) sodium hydroxide $(\mathrm{NaOH})$ in the ratio of 1:1:98. Three test tubes marked as test, control and blank were marked first containing 100 microlitre of sample, 900 microlitre of distilled water and 3 milliliter of alkaline reagent, second containing 1 milliliter distilled water and 3 milliliter alkaline reagent and last containing 4 milliliter distilled water. Tubes were incubated at $25^{\circ} \mathrm{C}$ for 30 minutes and then added with 300microlitre of FollinCiocalteau reagent (1:1) following incubation at $37^{\circ} \mathrm{C}$ for 10 minutes. Appearance of blue color and optical density was recorded at 560 nanometer.

\section{Thin layer chromatography (Sherma et al.,} 1991)

The thin layer chromatography was performed to identify the amino acid composition of the protein synthesized. The glass slide was covered with the silica gel and baked at $110^{\circ} \mathrm{C}$ for one hour. The mixture of n-Butanol, acetic acid and distilled water was prepared in the ratio of 5:1:3 as mobile phase. The slide was added with a drop of protein 
mixture and dipped in the mobile phase for an hour, dried and sprayed with ninhydrin and again dried until the appearance of blue spots. The amino acids were then conferred from the retardation factor $\left(R_{f}\right)$ values.

$$
\mathrm{R}_{\mathrm{f}}=\frac{\text { Distance travelled by the spot }}{\text { Distance travelled by the solvent }}
$$

\section{SDS-PAGE (Zeitung, 2012)}

The SDS-Page was performed to determine the molecular weight of the proteins (GeNei, Bangalore). Initially the vertical glass apparatus was assembled ensuring that it was completely leak proof. 5 milliliter of separating gel mixture was mixed with 50 microlitre of ammonium per sulphate (APS) and filled into the apparatus using a pipette leaving 2 centimeter of space on the top. This was allowed to solidify for 30 minutes and washed with water.

2 milliliter of stacking gel was mixed with 20 microlitre of ammonium per sulphate and filled into the apparatus. The gel was stacked with a comb and allowed to solidify. Meanwhile, 25 microlitre of sample was added with 15 microlitre of loading buffer which lead to denaturation of sample in boiling water bath for 5 minutes. Then, the comb was removed and the wells were washed with water.

The wells were loaded with the sample and the upper and lower chamber was filled with $1 x$ TAE (tris-acetic acid-EDTA) buffer. The electrodes were connected and the apparatus was run at 180 volt for an hour. Then, the gel was removed and destained overnight in destaining solution containing methanol, acetic acid and distilled water in the ratio of $1: 1: 8$.

The gel was observed for appearance of bands.

\section{Results and Discussion}

\section{Isolation of Saccharomyces sp}

The Saccharomyces sp. was isolated from bread sample on potato dextrose agar. After 3 days of incubation the plate was observed with mixed population of organisms. Each colony was further streaked separately to obtain a pure culture. The dominant species in bread making is Saccharomyces cerevisiae (Martini et al., 1998).

\section{Identification of Saccharomyces cerevisiae}

\section{Colony morphology}

The pure culture of Saccharomyces sp. was obtained on potato dextrose agar. The organism was visualized as smooth, glistering, flat, moist, cream colored colonies of oval shape with an entire edge as observed in (Figure 1).

The organism was confirmed with the similar findings of (Yadav et al., 2016). Colony morphology is a method that is used to describe the individual characteristics of an individual organism on a petri dish used for identification (Hulkova et al., 2012).

\section{Yeast viability test}

The yeast viability was performed using methylene blue staining. The viable cells were observed to be colorless whereas the dead cells took up the stain and appeared blue in color as shown in (Figure 2). Cell viability is usually defined as the ability of an organism to reproduce and form a colony. This is measured by analyzing the image after staining the cells with dyes specific to their metabolic activity (Sami et al., 1994 and Mastuoka et al., 2002). Among all dyes, methylene blue reacts with the oxidoreductases enzyme of viable cells (Sami et al., 1994). 


\section{Lactophenol cotton blue staining}

This was carried out to study the microscopic structure and finally identify yeast. The organism was elliptical shaped and some cells were observed to show budding as in (Figure 3). Thus, the organism was identified as Saccharomyces cerevisiae. Yeasts reproduce by budding and this can be observed under microscope via LCB staining (Yadav et al., 2016) whereas $S$. cerevisiae in its vegetative form is egg shaped and elliptical (Becze et al., 1956).

\section{Test for hydrolysis of urea}

This test was carried out on Christensen's urease agar and the organism was found to be negative for urea hydrolysis as visualized in (Figure 4). The urease activity is indicated by liberation of ammonia when test organism is cultivated with urea as a substrate (Randhawa et al., 1977). This urea is toxic and its fermentation causes liver diseases (Bisson et al., 1991).

Table.1 Retardation factor values of amino acids identified from single cell protein

Thin-Layer Chromatography of proteins

\begin{tabular}{|c|c|c|}
\hline EXTRACT & $\mathbf{R}_{\mathbf{f}}$ VALUE & AMINO ACID \\
\hline Apple & 0.30 & Glutamic acid \\
\hline & 0.69 & Phenylalanine \\
\hline Orange & 0.15 & Lysine \\
\hline & 0.38 & Alanine \\
\hline & 0.61 & Valine \\
\hline Tomato & 0.38 & Alanine \\
\hline & 0.69 & Phenylalanine \\
\hline Peas & 0.53 & Methionine \\
\hline
\end{tabular}

Fig.1\&2 Identification of Saccharomyces cerevisiae

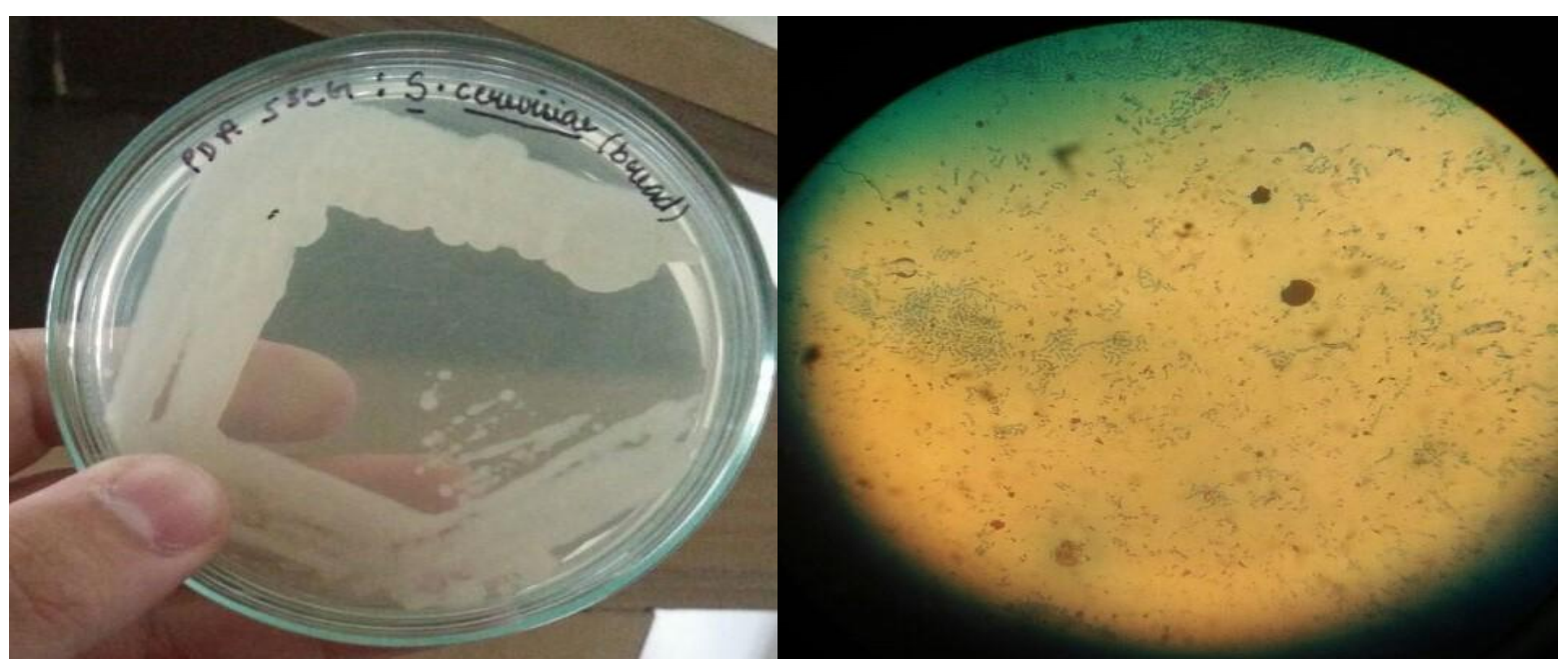

Pure culture of Saccharomyces cerevisiae

Methylene blue staining 
Fig.3. Lactophenol cotton blue staining



Fig.4\&5 Christensen's urease agar slants

Bismuth sulphite agar slants
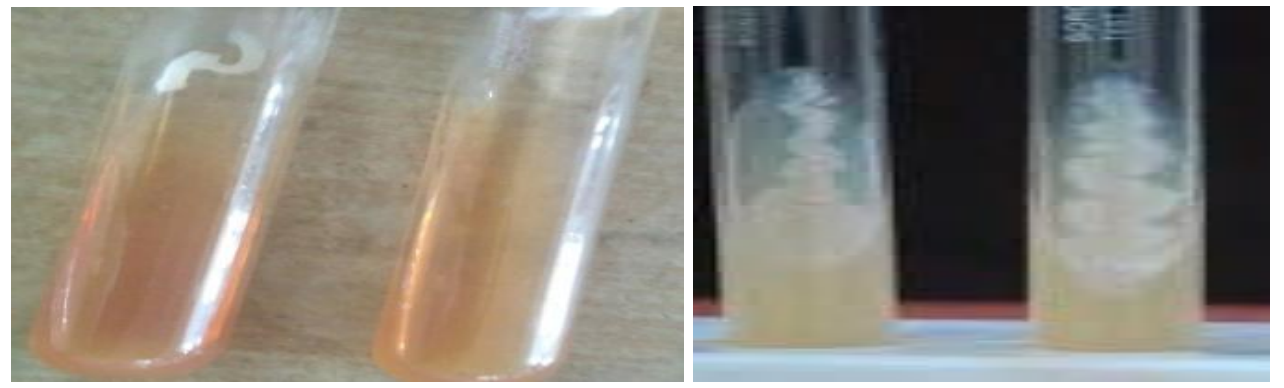

Fig.6 Sample extracts (Preparation of sample extracts and fermentation medium)

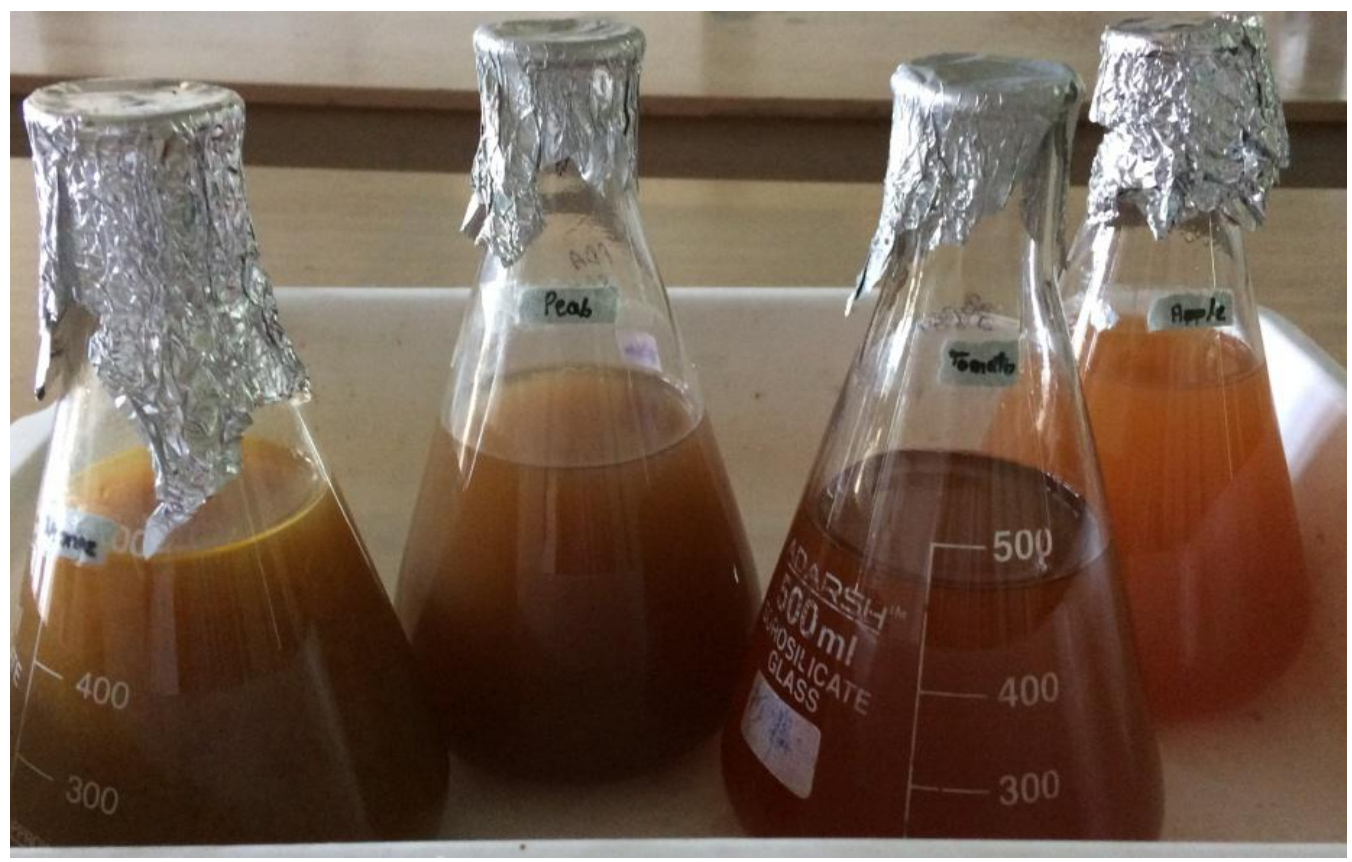


Fig.7 Fermentation medium

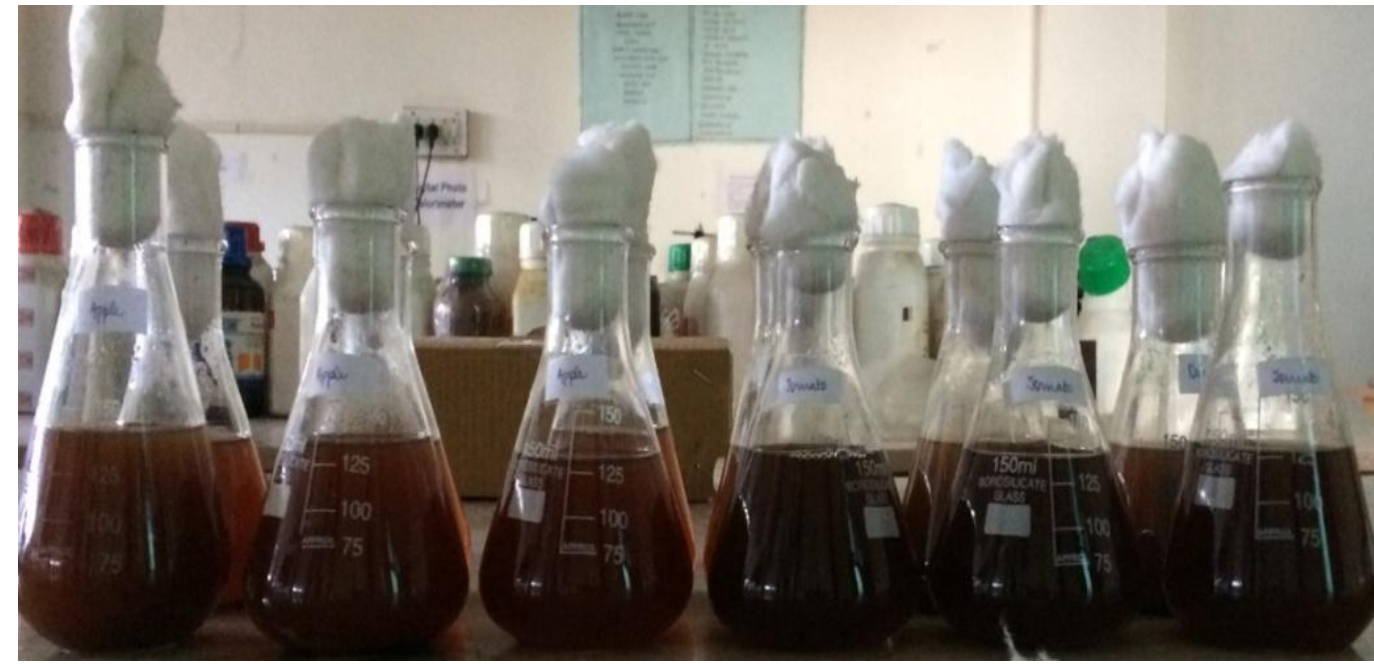

Fig.8, 9\&10 Fourth day incubation, Sixth day incubation \& Eighth day incubation
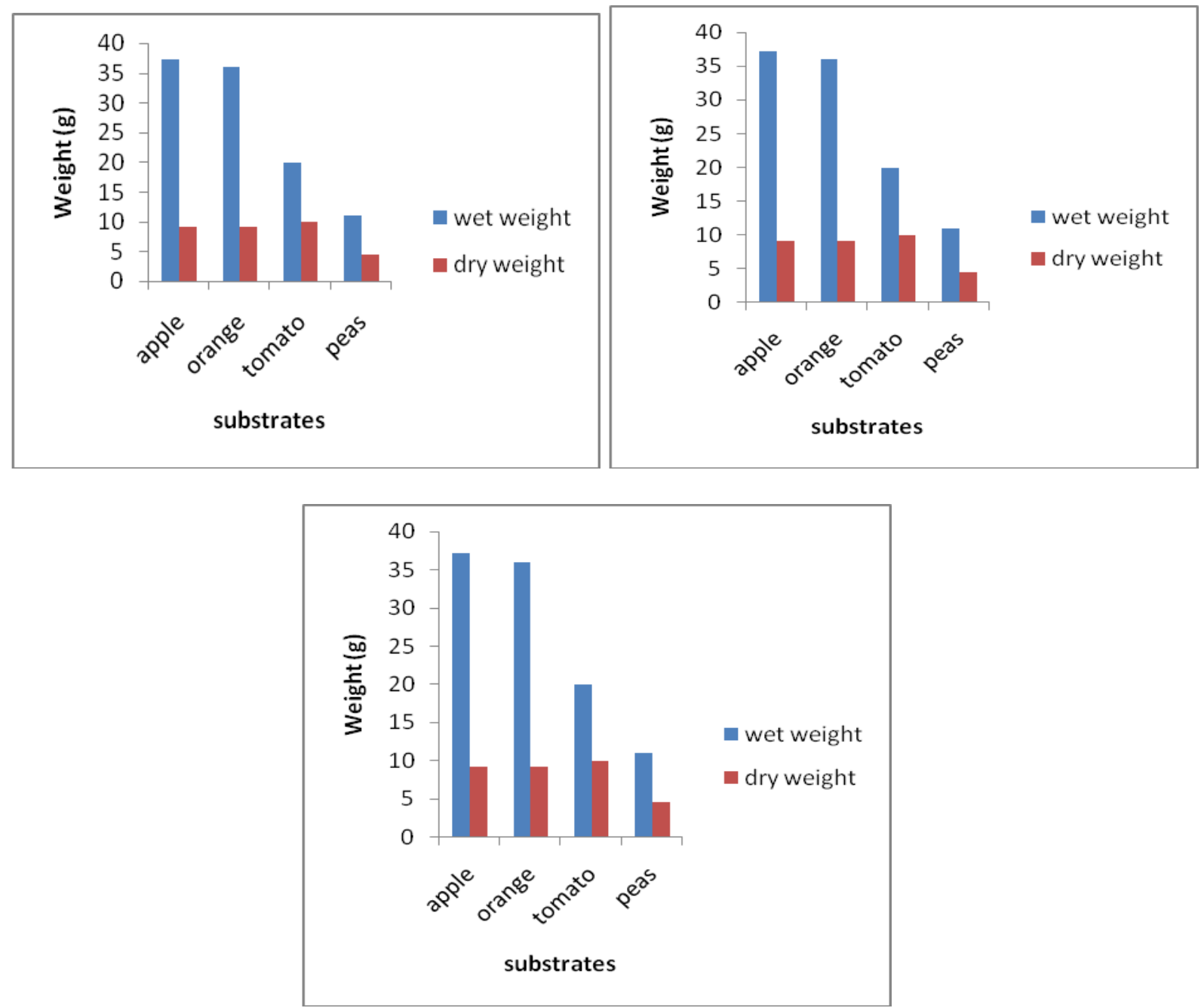
Fig.11 \& 12 Apple \& Orange (Estimation of protein content by Lowry's Method)
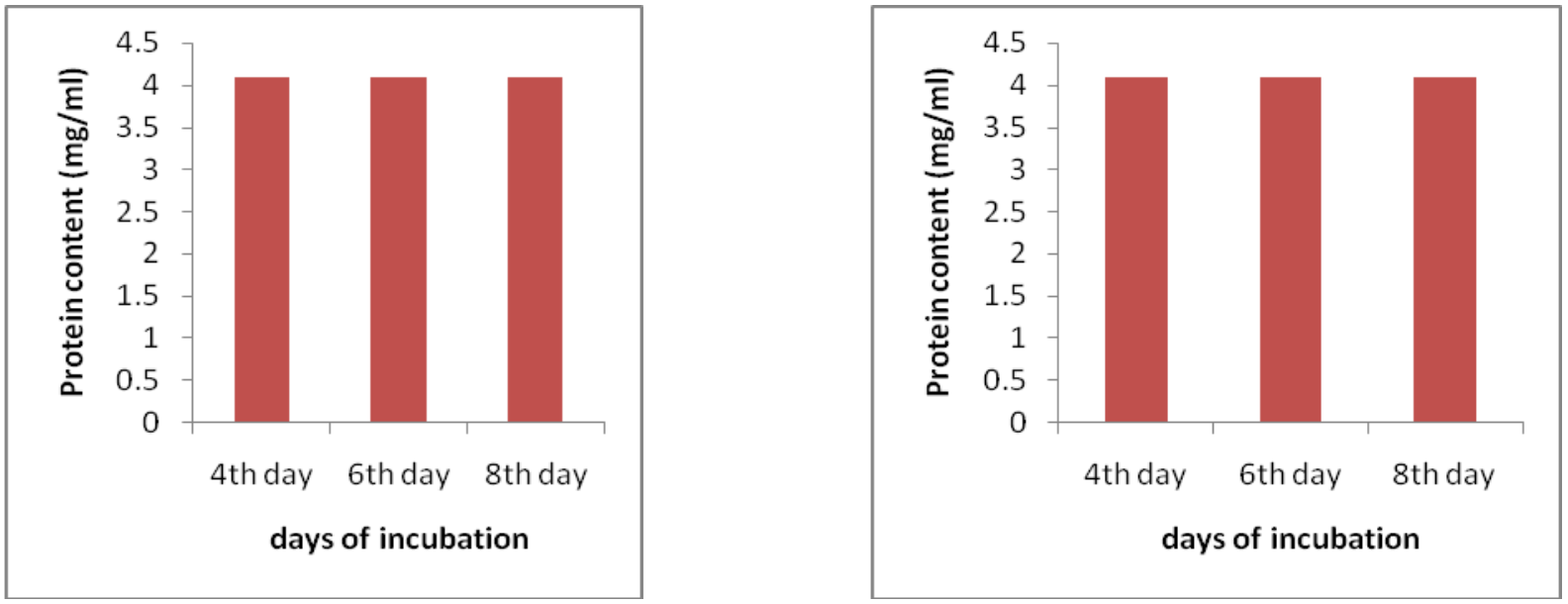

Fig.13\&14 Tomato \& Peas
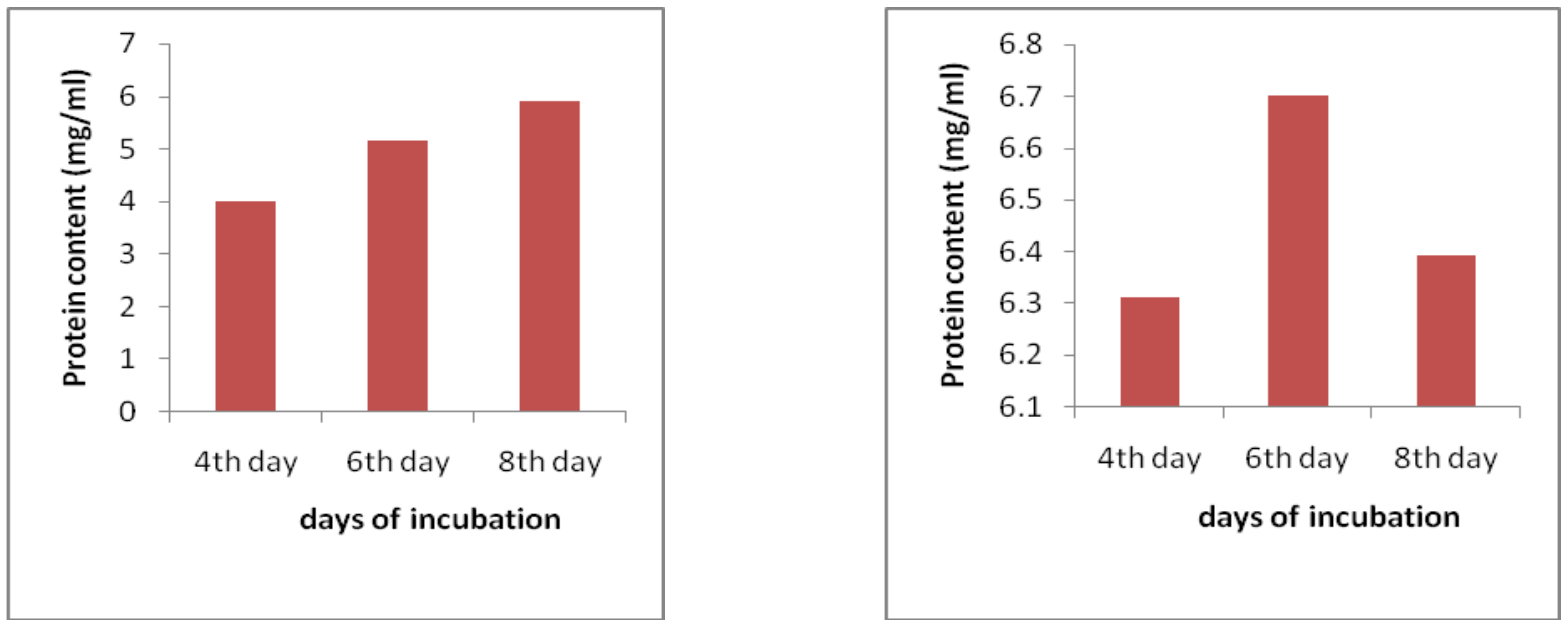

Fig.15 SDS- PAGE of SCP

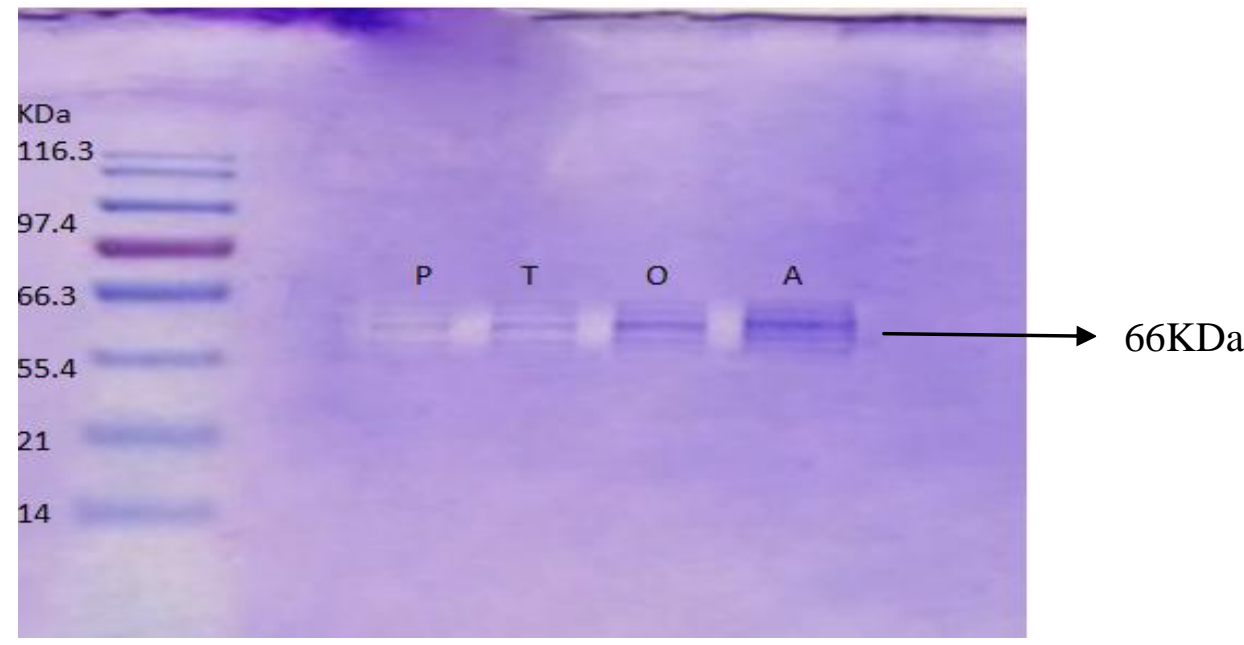




\section{Hydrogen sulphide production}

This test was carried out on bismuth sulphite agar and the organism was observed to be negative for hydrogen sulphide production as no color change was observed (Figure 5).

$\mathrm{H}_{2} \mathrm{~S}$ is a malodorous compound and can be produced by yeasts during fermentation (Rauhut et al., 1993).

\section{Preparation of sample extracts}

The sample extracts were prepared by degrading fruit and vegetable peels with 10 percent hydrochloric acid following incubation in boiling water bath. The extracts were filtered using muslin cloth. These were utilized as carbon and nitrogen sources for fermentation (Chandak et al., 2014).

\section{Fermentation and harvesting of SCP}

The sample extracts were added with the required nutrients to obtain glucose supplemented fermentation broth; $\mathrm{pH}$ was adjusted to 5.5, distributed among 3 conical flasks, autoclaved and cooled.

Each flask was added with 2 milliliter of $S$. cerevisiae culture and incubated for an interval of 4-6-8 days. S. cerevisiae has positive image with consumers and considered as a safe source of food processing.

This is recognized as nutrient supplement because of its high content of vitamin-B, essential amino acids and trace minerals. Thus, considered as an alternative source of proteins for consumption (Peppler, 1990).

\section{Protein estimation and analysis}

The protein fermented was procured through filtration and processed for physical and chemical analysis.

\section{Physical analysis}

The fermented product was physically analyzed for wet and dry weight and the maximum biomass was observed on final day on fermentation as shown graphically in (Figure 8, 9 and 10). The cell density can be quantified as grams of wet or dry weight per liter of sample and dry weight measurement usually gives a much more consistent result (Wang; 1988).

\section{Chemical analysis}

The fermented protein was quantified by Lowry's method represented graphically in (Figure 11, 12, 13 and 14) from each substrate. The maximum protein measured was $6.7 \mathrm{mg} / \mathrm{ml}$. on sixth day of fermentation from peas peels. Apple and orange gained maximum concentration on fourth day which remained constant till eighth day whereas the fermentation of protein from tomato lasted for 8 days. (Dhanasekeran et al., 2011) also observed the highest protein concentration on the last day of fermentation whereas 3.45 milligrams per milliliter of protein was observed from biomass of $S$. cerevisiae on fourth day of incubation (Manivasagan et al., 2017).

\section{Thin layer chromatography}

The single cell protein obtained from fruit and vegetable peels using $S$. cerevisiae constituted a mixture of both essential and non-essential amino acids. The identified amino acids have been listed in (Table 1). The identification of amino acids from single cell protein using thin layer chromatography was employed by (Mridul et al., 2017) and (Yunus et al., 2015) reported similar results.

\section{SDS-PAGE}

In the present investigation, the single cell protein was observed to have a molecular 
weight of 66 kilo Dalton (KDa) as observed in (Figure 15). However, the band resolution varied from substrate to substrate. The analysis of single cell proteins have always been challenging and the profiles prove that they are phenotypically similar (Wu et al., 2011).

\section{References}

Acharya T. 2014. Lactophenol cotton blue (LPCB) mounts: principle and staining protocol. Microbe Online. Microbeonline.com/lactophenol-cottonblue-lpcb-mounts-principle-stainingprotocol/.

Becze D and GI. 1956. Yeasts I: Morphology a microbiological process report. Applied Microbiology 4: 1-12.

Bisson LF and Monterio FF. 1991. Amino acid utilization and urea formation during winification fermentation. American Journal of Enology and Viticulture 42: 199-208.

Chandak AM and Uchakalwar PR. 2014. Production of single cell protein from fruit wastes by using Saccharomyces cerevisiae. International Journal of Advanced Biotechnology and Research 5: 770-776.

Dhanasekeran, Lawanya, Saha, Thajuddin, Panneersalvam. 2011. Production of single cell protein from pineapple waste using yeast. Innovative Romanian Food Biotechnology 8: 26-32.

Gervasi T, Pellizzeri V, Calabrese G, Bella G and Dugo G. 2018. Production of single cell protein from fruit and agricultural waste using Saccharomyces cerevisiae. Natural Product Research Journal 32: 648-653.

Hulkova M, Vopalenska I and Palkova Z. 2005. The morphology of Saccharomyces cerevisiae colonies is affected by cell adhesion and budding pattern. Research in Microbiology 156:
921-931.

Lowry OH, Rosenbrough NJ, Farr AI and Randall RJ. 1951. Protein measurement with the Folin-phenolic reagent. Journal of Biological Chemistry 193: 265-271.

Manivasagan V, Rajeshwari M, Monisha C, Akalya V and Suryaprabha S. 2017. Identification of single cell protein producing properties from fruit waste. International Journal of Engineering Research and Technology 6: 95-98.

Martini V and Martin A. 1998. Saccharomyces. Meyen ex Reese- The Yeasts: 358-371.

Matsuoka H and Oh KB. 2002. Rapid viability assessment of yeast cells using vital staining with 2- NBDG, a fluorescent derivative of glucose. International Journal of Food Microbiology 76: 47-53.

Mridul U, Kumaresan P, Basher $\mathrm{T}$ and Kathiavel P. 2017. Production of single cell protein and polyhydroxyalkonate from Carica papaya waste. Arabian Journal for Science and Engineering 42: 2361-2369.

Peppler. 1970. Yeasts in food and beverages. ISBN: 978-3-540-28388-1: 453.

Rauhut D. 1993. Yeasts- production of sulfur compound. Wine Microbiology and Biotechnology (ed. G.H. Fleet), Harwood Academic Publishers, Switzerland pp:183-223.

Randhawa HS and Palival DK. 1977. Rapid method for detection of urea hydrolysis by yeast. Applied and environmental microbiology 33:219-220.

Sami M, Ikeda M and Yabuschi S. (1994). Evaluation of the alkaline methylene blue staining method for yeast activity determination. Journal of Fermentation and Bioengineering 78: 212-216.

Sherma J and Fried B. 1991. Handbook of Thin-Layer Chromatography. New York: M. Dekker, third edition pp: 491493. 
Tong Z and Herbert F. (2004). Quantification of Saccharomyces cerevisiae viability using BacLight. Biotechnology Letters 26: 989-992.

Wang NS. 1988. Biochemical engineering laboratory manual: ENCH 485. Measurement of cell biomass concentration. Department of chemical and biochemical engineering, University of Maryland, College Park. MD. 20: 742-2111.

Wu M and Singh AK. 2011. Single cell protein analysis. Current opinion in Biotechnology 23: 1-6.

Yadav SS and Tiwari A. 2016. Isolation, identification and characterization of
Saccharomyces cerevisiae strains obtained from sugar cane juice and $\mathrm{H}_{2} \mathrm{~S}$ screening from different areas of India. International Journal of Advanced Technology in Engineering and Science 4: 303-309.

Yunus FN, Nadeem M and Rashid F. 2015. Single-cell protein production through microbial conversion of lignocellulosic residue (wheat bran) for animal feed. Journal of Institute of Brewing 121: 553-557.

Zeitung NZ. (2005). Interview with Ulrich Lammli in London. Neuen Zurcher Zeitung Folio, 11.

\section{How to cite this article:}

Savi Ahuja and Poonam Kumari. 2019. Production of Single Cell Protein from Fruit and Vegetable Waste using Saccharomyces cerevisiae. Int.J.Curr.Microbiol.App.Sci. 8(02): 114124. doi: https://doi.org/10.20546/ijcmas.2019.802.014 